\title{
Rethinking Political Communication
}

'Content', is hardly something contemporary political culture could be said to lack. Political news, opinion and disputation fill newspapers and broadcast media. Platforms such as Facebook, Medium, Reddit, Twitter, Podcasts and You Tube have given rise not only to new kinds of political participation, participants and audiences but also to new genres of political argument and expression. The last decade has therefore seen an extraordinary and far-reaching transformation of the volume, sources and the styles of political communication. The effects of all this on our democracy are, at present, definitely mixed. More information has been met by more misinformation. The increased speed of reporting on politics has decreased the span of attention and the time for reflection. Expanded participation in political discussion has also improved opportunities for those who want to exploit free speech for sectarian advantage (or to abuse it for their own amusement).

The freedom and the capacity for people to think for themselves is - it goes without saying - a source and a goal of democratic politics. That necessitates in turn the freedom and capacity to express those thoughts publicly, to take part in formal and informal discussion and debate about political decisions, and to argue over the quality and nature of economic and social life. It does not follow, however, that just any political talk whatsoever is necessarily and always good for democracy. Mendacity, stupidity and flippancy can manifest in political speech as much as any other, and like bad currency they drive out of circulation the tokens of good communication. It is therefore tempting to see in contemporary political communication a problem of inflation too many people, saying too much, too loudly or, as Plato put it when complaining of the Athenian Assembly, 'shouting or hammering their disapproval and approval, grossly exaggerated in either case, of the things that are said and done'. That temptation is to be 
avoided. Our choice is not between acquiescence to elite authority on the one hand, and acceptance of our cacophonous public sphere on the other. If we refuse that choice we can instead turn our attention to thinking carefully about how contemporary communications technologies are changing the ways in which we experience and take part in democratic politics.

Such re-thinking is necessary because technologies of political communication do not simply reflect or transmit political ideas and opinions. They give shape to thinking and are the means by which we 'educate, agitate and organise'. But, different means of communication make possible different kinds of answers to the questions of who will be educated, what will agitate them and how they will be organised. Digital media are new and still rapidly evolving but they have already changed the kinds of ideas that can have currency in our political culture, and the ways in which people apprehend, respond to and use them. They have intensified an ideological 'culture war' and given new life to paranoid and conspiratorial thinking from the daft (such as flat-earthers) to the wicked and sinister (anti-semites and neo-fascist monarchists). ${ }^{1}$ But digital communication has also expanded the range of people who can play an active part in the refinement of our collective political intelligence, feeding creativity, enhancing political education and giving rise to new kinds of dynamic and adaptive political alliance. The challenge is to work out - through conceptual reflection, practical action and experiment - how best to agitate, educate and organise with these new tools, to develop new rhetorical styles and strategies, and to plug these into structures and processes of political organisation and struggle in ways which can enhance democratic freedom and the capacity to exercise it.

In what follows I first consider how political communication is today commonly thought of by progressives as a problem. While acknowledging the seriousness of these problems I argue that 
the way we frame them means that we risk succumbing to the anti-democratic temptation which just wants the noise to stop. Such a framing hinders our understanding of new media and the search for answers to the question of how to speak well and loudly about radical democratic politics today. I therefore introduce a way of thinking about politics and communication which I think helps us think things through better, consider some of the challenges posed for us by the political culture of social media and look at some examples of the ways it is being successfully used by new kinds of political actor emerging from the Right.

\section{The Problem and the Question}

Early enthusiasm for the 'digital public sphere' has - in the face of insurgent populisms across Western democracies - given way to a feeling among many liberal and radical democrats that the public sphere is in total crisis. Expressions of that feeling tend to focus on three broad sets of issues. The first of these is the way social media have enabled those with most resources to leverage undue and unaccountable influence on the public sphere. Of particular note here are widely publicised allegations - such as those involving the company Cambridge Analytica that well-resourced and cynical political campaigns have been able to access and use psychometric data derived from social media in the design of political advertising targeted at precise segments of the population. In addition to giving the few an unfair advantage over the many, two problems are usually highlighted: that such communications are unjust because manipulative, cleverly appealing to the emotions in a way that suppresses individuals' rational reflection; that the use of 'dark ads', seen only by those they are aimed at, enables political actors to bypass the public sphere and the scrutiny, debate and rebuttal that might be generated there, allowing all kinds of propaganda and incitement to spread unquestioned. The latter concern overlaps with the worry that social media create 'bubbles' in which we see, hear and 
read only that which reinforces our current beliefs, ceasing to engage in the kind of reflexive revision of beliefs thought essential for rational democratic deliberation. What unites all these concerns, then, is their underlying sense that the public sphere is becoming dominated more than usual by irrational ways of thinking.

A second and related area of concern, is that of "fake-news". This label is attached to different phenomena. One of these is false stories created with the intention of misleading people. Examples here include Russian government-sponsored 'troll-farms' of the kind that are the subject of indictments by US Attorney General Robert Mueller in his investigation into interference in the 2016 US Presidential election. These consist of people paid to cultivate social media profiles and then insert into blog-posts and online discussions particular news stories, political opinions or other claims in a twenty-first century version of Nixon's 1950 'whispering campaign'. Another kind of 'fake news' is political 'clickbait' - the creation of websites and stories created with the simple goal of generating web-traffic and thus advertising revenue. Examples include the work of young entrepreneurs in Veles, Macedonia who, during the 2016 Presidential election, created websites with misleading names such as NewYorkTimesPolitics.com, on which they published pro-Trump 'news' articles which they assiduously circulated on social media, generating a decent income. ${ }^{2}$ What unites the set of concerns about 'fake news' is the view that the public sphere is being corrupted by communication with an instrumental goal - political or financial advantage - rather than the ethical goal of increasing public understanding and honestly searching for the common good.

A third and final set of issues concerns the extent to which unregulated online communication enables or even encourages speech which exceeds the limits of what a democratic commitment to discussion and debate can tolerate. Platforms such as Twitter, Facebook and Reddit have 
been urged - and in some cases required - to remove users whose communication is threatening or aggressively prejudiced: racist, sexist, homophobic, transphobic and so forth. That there is a lot of this about is undeniable. Abuse of women politicians on Twitter, for example, is well documented. ${ }^{3}$ It is also clear that while some of this kind of harassment is indicative of the attitudes of a few individuals, some of it is planned and implemented as part of a political strategy. ${ }^{4}$ The core concern here is two-fold: that such speech actions are harmful in themselves, a kind of assault, and that their goal or effect is to prevent some kinds of people from participating in public discussion and debate. Social and cultural inequalities are thus reproduced in the political public sphere which rather than being a space where citizens meet as equals becomes a means of sustaining that inequality.

Charges of irrationality, instrumentalism and inequality are, then, at the core of the progressive critique of contemporary political communication along with proposed remedies: the revision of electoral law so that it can better control campaign activity; more effective regulation of social media companies by, for example, treating them as news organisations; new protections and means of legal redress for victims of harassment. Now, while the power of psychometrics are over-stated, there need be no doubt that social media are increasing the spread of falsehood, encouraging the unchecked declaration of untenable opinion, and a venue for widespread harassment. Regulatory and legal remedies are certainly required. But we do need to pause here. The way these problems and remedies are often framed tends to construe them either as intrusions into an otherwise fair and free public sphere or as undermining the ongoing effort to build one. That is to say, critique is guided by an idealised version of the public sphere that was the product of a particular form of democratic organisation reliant on print and some kinds of broadcast media. Accordingly, it tends to assess the new by measuring how far it departs from the old, and to demand regulation which can make the new be more like the old. New 
forms and styles of political communication are construed as breaches of the current rules leading to a search for ways to enforce the rules better and for new rules to cover new infractions. Is this adequate for grasping and responding to our current situation? Is there not a risk that in thinking the new in the terms of the old, we end up adopting a position that is reactive and defensive in ways that disable us from seeing what is really happening and working out how best to respond? I see two problems in particular. The first is practical: that while we check the rule book and propose revisions, our opponents are busy winning by breaking the old ones and are in effect writing the rules for a new game of their own devising. The second is conceptual: the focus on managing the overall culture of political communication means that we are not thinking about how to do it - how to adapt to a changing political culture, and how to develop and use new technologies to create new forms and styles of rhetoric and argumentation in ways that increase democratic capacity. We are assuming that we are hegemonic, that nobody could seriously or sincerely contest the way in which we think the public sphere and politics should work, and we are letting that assumption do our political and ideological work for us. It isn't working.

To be clear, none of this is intended to encourage complacency about the irrationality, instrumentality and inequality produced and sustained by some parts of our culture of political communication. On the contrary, these must be acknowledged as ethical as well as legal challenges but also as a pressing political problem which is to say, one which concerns the forms taken by power and the ways in which it can be wielded and contested. In addition to thinking about how to stop others wielding that power we need to think about how to wield it ourselves. We have to think about how to act not only on the digital public sphere but within it, in ways that can defeat manipulation, promote factual and rational analysis and defend our people from attack. 
An analogy might help here. The extension of the franchise to all adults was not just a quantitative change in British elections. It transformed how British politics took place and what it was concerned with. It was an 'amendment' to the constitution which transformed the significance and value of other parts of that constitution and their relationships with each other, changing the ways in which publics were formed and connected to government, how political parties worked, the relationship of Commons to Lords, the kinds of political demands that were counted as legitimate, the scope of rights and thus also the extent of state action. How people thought about and engaged with politics changed irrevocably. Anyone doing politics in the old way was overwhelmed. Those which survived did so by developing new kinds of rhetoric, new ways of speaking to people, and new venues through which to do it, cultivating a culture of party politics. My concern is that our critique of emerging tendencies within contemporary political culture is not adequate to the scale of the transformation underway and that we risk being so far on the wrong side of history that in the future it will be us whose 'strange death' will be the topic of scholarly debate.

Changes in the technologies and uses of communication also alter the 'constitution' of political society. The expansion of online platforms has changed who takes part in political debate, how they take part and what they think they are doing when they are doing it. That isn't just an amendment to the established way of doing things. It is a change in the relationship of communication to other political institutions and practices and thus a change in them too. The question for political analysis is how to understand that change - how people's relationship to government and politics is being altered, how politics is becoming something different from what we thought it was. The challenge for progressive political practice is not the restoration of things to the way they were but the development of platforms, styles and strategies for 
working in this new context, in ways which not only enable us to defend past gains and check opponents but also to find potential for enhancing democratic capacities.

\section{Communication, Party and People}

If we reframe the problem in this way then the questions we have change also. In addition to asking why something is being allowed to happen, and what can be done to prevent it, we also ask for a thicker understanding of the relationship of communication technologies to politics. A starting point for that is a typically provocative 2007 essay by Regis Debray in which he proposed that political movements are an ensemble of three things: people, institutions and 'tools of transmission'. ${ }^{5}$ In the case of socialism those people were members and supporters of the working-class brought together in institutions such as parties, trade unions, corresponding societies and workingman's associations linked to a physical infrastructure including buildings in which, as Debray puts it, one could access 'a library, newspapers, evening classes and lectures' and where archives of previous classes, debates and discussions were kept. The 'tools of transmission' were newspapers, pamphlets and books, a vibrant print-culture linked to a powerful oral culture of rallies, speeches and congresses, songs, stories and sermons. In combination these constituted the a movement and its thinking into which people could be inducted, learning where it had come from and where it might go. It also gave rise to a vocabulary and a language - ways of describing and analysing social and political conditions, concepts to help grasp them critically and forms of presentation and argument for communicating that understanding persuasively.

People could learn that language, use and share it and in doing so were not only describing a politics but also being part of its development. For Socialism, the printed word in the form of 
the pamphlet, the book and the party newspaper were not only a means of distributing an ideology. They were also the embodiment, and the means to an enactment, of its core propositions: equality, collective self-organisation, liberation. The cheap and readable pamphlet educated readers otherwise excluded from education and was allied to lectures, seminars, discussion groups and debates affirming that everyone could understand the world: that the worker was a thinker, that anyone could talk, argue and decide about politics, and that the division between mental and manual labour could be overcome. All this was of course also the way in which the movement could coordinate people in political struggle. Tools of transmission allied to institutions such as the party and the union could turn people out on streets or on strike, could direct their action and deliver their vote leading to change in the institutions of government and economy. The party newspaper, for example, mixed propaganda with the dissemination of news and the presentation of an analysis, 'transforming', in Debray's words, 'a conception of the world into small change, a philosophical system into everyday slogans' and enabling individual energies to be integrated with the practice of party and political leadership.

So deeply was the high-water mark of socialist party politics associated with this kind of print culture that Debray thinks it could not survive when media systems developed from a means of transmitting ideas into a commercial mass market for images. He has a point. In the UK the Party newspaper, the caricature of Socialist Worker aside, is a thing of the past. Notably, Labour Weekly closed in 1987 the same year that Labour ran a widely applauded but unsuccessful 'professional' - meaning media-driven - election campaign centred on promotion of the personality of the party leader. The rise of twenty-four-hour news and the beginning of the shift from print to digital, triggered a transformation of party communications that was also a change in the form of the political party. The (always fraught and contested) communication 
of information about society up and down from the grassroots of a movement to its leadership was replaced with the identification of 'public opinion' via the opinion poll and the focusgroup. The public was no longer conceived of primarily as a body of citizens but as a collection of individuals making up an audience. This was not simply a change in campaign practice. It was a change in ideology, a replacement of the ideal of the self-organising citizen seeking to increase and exercise collective power with that of the individual consumer weighing up each party's 'offer', expecting efficient and effective 'delivery'.

In this context, the dissemination by a party of information and ideology to a mass membership came to seem a waste of time and a misdirection of energies better aimed at cultivating rigorous message discipline and the arts of 'news management'. That was itself a way of adapting to a voracious media and to a political culture in which, as the sociologist Jeffrey Alexander puts it, the public sphere is not so much a forum for rational deliberation as a public stage. ${ }^{6}$ That stage, he argues, hosts performances (sometimes contentious) of ongoing 'social dramas' which publics assess in light of past and present performances, their shared repertoire of recognisable parts and plays, controversies and characters which performers (be they party leaders, celebrity activists or columnist commentators) must play or be made to play: the bold reformer, risking it all to go up against orthodoxy; the teller of truths that others dare not tell; the loyal and reliable hand who will do what is needed in times of trouble; the tough guy ready to take on the bad guys; the Machiavel; the jester; the traitor; the solider; the nanny; the wise owl. Political campaigns place such figures within larger historical 'narratives' that dramatise answers to questions about who we think 'we' are and what we think is happening, and into which politicians try to cast themselves as grand protagonists. Consider, for example, Boris Johnson, in the summation of the BBC live debate on the EU referendum calling for our 'Independence Day'. ${ }^{7}$ These were the words of a fictional American President, from the film 
of the same name, the drama of a people recalling their foundation myth as preparation for their final conflict against mute and monolithic aliens. In evoking this performance Johnson, consciously or not, cast Brexit as a particular sort of heroic drama which, despite its postmodern blurring of national cultures, fiction and reality, resonated with those willing and able, perhaps needing, to recognise themselves in that call for national recreation and renewal. ${ }^{8}$

Politics has always had a dimension of dramatic spectacle. But the changing stages on which it can play out have changed the way the narrative unfolds. The period of televisual broadcast politics - characterised by tight news management and focus on leadership personalities peaked in the nineteen-nineties and gave rise to a form which still dominates the theory and practice of the main broadcast and print media outlets. In them, the character of the proper, reasonable and reliable politician is quite tightly circumscribed, and political journalists are like expert theatre critics who interpret the play for us and tell us who is acting well, performing properly, and who is not. Today however that division of labour is falling apart. In the last decade, to take one example, what started as 'below-the-line' comments in online newspapers have developed into genres such as the political blog enabling all sorts of people to become opinion columnists, bypassing editorial gatekeepers and even finding self-employment as pamphleteers and polemicists. Thomas Clark, an English tutor based in Yorkshire, blogs under the name Another Angry Voice. During the 2017 election campaign two of his articles were in the top three most shared online - far in excess of anything from the newspapers. ${ }^{9}$ Blogs like Clark's - along with larger sites hosting multiple authors such as Guido Fawkes and Westmonster on the Right, The Canary and Evolve Politics on the Left - increase the number of stages upon which politics goes on show and by so doing also increase the range of roles which political actors can play and be recognised as plausible. That undermines the 'vertical integration' of the political 'marketplace' so assiduously developed by the 'cartel parties' and 
their official supporters in the news media. ${ }^{10}$ Avant-Garde and retro-revivalist performances that once seemed way, way off Broadway with no chance of an audience, provincial companies that would never get a booking in the urbane theatres of a cosmopolitan capital, can now all find an audience, grow it, amplify it and help it to recognise itself. Some have even done so to a degree that has compelled the national media to pay attention.

However, the break-up of the cartels of political culture and of their monopoly on what counts as right-thinking is not the definitive feature of the emerging culture of political communication, which enables something important in addition to the fragmentation or pluralisation of electorates and political audiences. What internet politics invites above all is the self-abolition of the audience. Everyone, anyone, who wants it, is invited onto the stage. Via the social media platform of our choice, each of us can play a role, however small, in the social dramas of our time. That is the development to be grasped. That is the phenomenon which is changing, and will continue to change, the way we understand our relationship to politics and to democracy.

\section{The Form of the Content}

If Debray is correct and part of the success and value of the culture of nineteenth-century socialism was the way it included people within a culture of egalitarian self-education then, surely, the means for inclusion and knowledge distribution afforded by digital culture are an opportunity for the recreation of what was lost in the age of the broadcast image. However, that is to reckon without the ways in which online platforms encourage a culture of competitive and acquisitive individualism. Onscreen the world is a series of things for me to open, close, delete and move at will. I can arrange the things upon it just as I please; I can watch a political 
speech, pausing, rewinding, switching between it and a commentary upon it, my own writing about it, my email, my Twitter timeline. The things of the world I have accessed via the computer become objects, defined by the relationship to me that I give them (with anything unexpected or undesired experienced as an intrusion into my space and to be expelled or blocked immediately). Perhaps this is one source of the sadism that too often characterises online behaviour. 'If the movie screen always directs toward', writes the media theorist Alexander Galloway, 'the computer screen always directs away. If at the movies you tilt your head back, with a computer you tilt in'. He evokes the legend of the Ring of Gyges, as told in Plato's Republic and which, because it makes the wearer invisible, raises the question of how virtuous we would be if we thought we could never be seen, caught and punished. But online, Galloway argues, the legend is inverted. 'The computer is an anti-Ring of Gyges. The wearer of the ring is free to roam around in plain sight, while the world, invisible, retreats in absolute alterity. The world no longer indicates to us what it is. We indicate ourselves to it, and in doing so the world materializes in our image'. ${ }^{11}$ That is to say, the computer lets us dress the stage, design the lighting, so that we appear as we think we want, and with the house lights up the world beyond the stage is hidden from view.

That individualisation of experience is given a further impetus by the ease and speed with which digital platforms convert communication into forms of capital which they invite us to accumulate. Through liking, following, sharing, upvoting and so on, the value of what we say can be measured in social or cultural capital (and in how much we have or lack compared to others). Blogs and YouTube videos can easily be converted from cultural into money capital through advertising or through the patronage of followers via systems such as Patreon. The civic goals of communication are (yet again) cut across by a commercial imperative which demands novelty and distinction. 
For these reasons, digital communication tends to promote a political culture in which selfexpression predominates over and, indeed, decomposes collective political ideologies of any kind. Online, the heroic (and its counterpart of the comic) performance of self-expression, the declaration and demonstration of a place on the stage (wherever that is and no matter how small), is a dominant register of political discourse. Those of us whose work gives us some little access to very minor roles on the main stages of the public sphere should not feel we have the right to judge those putting on a show of their own. There is a democratic dimension to this, there is empowerment and there is a strongly egalitarian aspect to the individual citizen having the chance to argue against the politician, the professional pundit or the professor. The problem is that it comes to seem as if self-expression is the goal of public political discourse, as if just saying stuff is an achievement in itself without need of a connection to a political movement, a plausible political demand or a strategy for persuading others to support it.

Indeed, digital culture erodes the distinctiveness of political thought and action. To speak at a political meeting is to do something different from what one is doing when speaking generally. To write a letter to a newspaper used to involve a specific effort and sometimes a distinct form of address. Online, the way we interact as citizens is indistinguishable from the way we deal with email, pay bills, communicate with family, joke with friends. Some platforms, such as Twitter, are simultaneously and often indistinguishably, work, citizenship, brand-building, socialising and private life. One of the causes of conflict online (and sometimes of public and official scandal) is that statements of an 'everyday' nature shared between friends have the same appearance as statements made in an organisational or official capacity. The former can then be taken to have the seriousness, the moral or political significance, of the latter, while people in their official role can hide their politics within an everyday mode of discourse. What 
is lost here is recognition of the fact that when we do democratic politics we are doing something distinct. It is not work, leisure or shopping. It is where we become something other and more than our selves, where self-interest develops beyond itself, and beyond even our natural social interest in the company and recognition of others, such that we are concerned for what is in the interest of all, for the good of what is in common.

It is in this part of our post-democratic political culture that the populist Right has prospered. It has grasped that the power of the medium lies in the fact that it allows a kind of political communication that is the opposite of that encouraged by broadcast media. The latter invites forms of address aimed at the broadest range of people, at an imagined entire public. It leads us to look for instances of the typical - 'Mondeo man', 'soccer mom', 'Worcester Woman' and to appeal to them by showing that we recognise their typicality, affirming that they are the norm, that what they want is what all should want, and that our policies will meet their needs. But online we can create our own profile, striving to believe in its atypicality, and looking for the audience that will applaud it. It may seem paradoxical given that part of the populist argument is that we should think of ourselves as first and foremost one part of a people, a nation or a race and that we should accept and conform to the natural impositions of our biological sex, but online the radical Right appeal to people on the basis that they are atypical, beyond the mainstream and part of a counter-culture. They invite and enable people to think of themselves as individuals who eschew orthodoxy and think for themselves, sceptical about the pronouncements of the officials in government, media and universities. Indeed, the core of their critique of liberalism is that, in their telling, it demands that we conform to our social identity, our class, race or gender. Supporters are enabled and encouraged to demonstrate, to perform, their rejection of such Liberalism and to enjoy what one Trump-supporting meme calls 'Liberal Tears'. Indeed, the way in which he affronts liberal sensibilities is central to the 
appeal of Trump. It gives supporters vicarious pleasure to see him take down a peg or two, an attitude so convinced that it is natural, normal and given. A related meme mocks liberals for relying on the argumentative technique of asserting 'the current year'. That's when somebody says something to the effect of 'it's 2018, how can you say, think, do this, how can this be allowed to happen'. The point is to expose the extent to which liberalism takes for granted its own hegemony even as it denies it, and in so doing to show to potential converts that what claims to be generous-minded universalism is in fact the expression of a particular cultural interest. $^{12}$

This is part of a much more extensive phenomenon. Three brief examples will have to suffice: Jordan Peterson, the Canadian psychology professor, now world-famous self-help author, critic of gender politics and left-wing academics, and advocate of the mythical re-enchantment of the world; 'Sargon of Akkad', real name Carl Benjamin, a thirty-eight year old who lives in Swindon, describes himself as a classical liberal, mostly agitates against Feminists, and who achieved infamy for abusive and unrepeatable comments directed at the Labour MP Jess Philips ${ }^{13}$; Paul Joseph Watson, a thirty-five year old from the North East now based in London and working for the world's finest purveyors of conspiracy theory and nutritional supplements InfoWars. Until recently Peterson was not widely known outside of Canada and certain parts of the internet; Benjamin and Watson are largely unknown to those over forty who don't share their politics (unless condemned to make a deliberate study of it). Why should we know about them? Consider the numbers. "Sargon" has seven-hundred and eighty-five thousand subscribers to his You Tube Channel. To put that into context, Newsnight has just over one hundred and ninety-eight thousand (which is one hundred and fifty thousand more than The Labour Party). His most watched video has been viewed $2.8 \mathrm{~m}$ times. The most watched Labour Party video has been seen six-hundred and sixty-seven thousand times. Peterson has just over 
one million followers on You Tube; his video 'Identity Politics and the Marxist Lie of White Privilege' has been viewed by 1.1 million at the time of writing (and he is estimated to earn $\$ 19000$ and $\$ 79000$ from supporters via Patreon). ${ }^{14}$ Watson has $1.2 \mathrm{~m}$ subscribers, and videos viewed as many as twelve million times. His June 2016, rhythmically rhetorical performance, 'The Truth About Brexit', has been viewed seven hundred and fifty three thousand times.

The videos these three make are not short, pithy pellets of multimodal propaganda. Watson's are often ten to fifteen minutes long; 'The Truth About Brexit' is a twenty-minute speech, mostly delivered direct to the camera). Sargon's regular feature 'This Week in Stupid' runs for thirty minutes to an hour. At the start of 2018 over half a million watched him engage in a live online debate with the North American fascist Richard Spencer, for over four and a half hours. Peterson's diatribe against identity politics is a lecture which runs for over two and half hours. Each of these prolific (and perhaps verbose) ideologues links the curious viewer to a much larger political-intellectual ecosystem including other videos, extensive subsidiary discussion, debate on Reddit and other forums, and further reading ranging from history books and evolutionary psychology (used to justify their gender politics) to various shades of conservative, right-wing and far-right political theory. It is a large and dynamic arena of international ideological production which includes events offline - conferences, conventions and lectures. In July of 2018 Peterson will debate with the celebrity atheist Sam Harris and the professional anti-immigration conservative Douglas Murray at the O2 Arena in London. Tickets cost from $£ 60.00$ to $£ 210.00$ It is billed by the promoters as 'the Woodstock of live speaking and debate'.

Sargon, Peterson and Watson - belong to different fractions of this new, New Right, and each exhibits a different political style (from Watson's populist sensationalism to Peterson's 
performance of academicism) but they share in common a mode of political selfdramatisation: they are individuals who will think the unthinkable, and say the unsayable, eschewing what they present as the merely fashionable or intellectually orthodox, suffering bravely the blows and the persecution of their enemies. That persona is a key part of their rhetorical strategy, an ethos of sober realism, and a demonstration of their ideology according to which the world is tragic and painful, civilisation is in decline, we are beset by decadence and barbarism, all a good man can do is stand on his own two feet, think for himself and defend that which is his - his identity, his property, his family (his nation, his people, his race).

But, crucially, what these performers do is more than simply tell people what to think. They also show them how to think in a particular way. Much of their content consists of polemical critique and analysis - sometimes at great length - of the errors and idiocies of their opponents. They demonstrate how to argue against them and offer a broad-based analysis of what is wrong with the world, who made it wrong, and how to make it right for yourself. In that sense they are educative, turning 'a conception of the world into small change, a philosophical system into everyday slogans'. They give their audience things to think with and things to do - ways of reacting against the world they believe to be unjust (such as pointing out every use of the 'current year'). This, then, is a way in which people, institutions and tools of transmission are assembled today.

\section{Conclusion}

Just as there is a means of production before any particular thing is produced, so there is a means of political communication which gives rise to particular acts of communication. And, 
like the means of production, the means of political communication creates 'definite social relations' between people, organising them in relation to each other and to their own political activity. Digital communication is affecting politics at this level. It isn't just a new way of doing an old thing but a change in what can be done and what value it has. In altering the stages, scripts and dramas with which we perform our politics for each other it is also altering what people know (or think they know) about politics, and how they feel about it. It has shifted the context against which they perceive themselves and their aspirations, the questions they ask and the kinds of answers they are prepared to entertain, the propositions and their proofs which give shape to what is politically thinkable.

Twenty-first century political communication builds on the 'personalization, informalisation and dramatization' which characterised fin-de-siecle political journalism by enabling everyone to do it for and to ourselves. That might involve nothing more than recirculating (sharing or retweeting or reposting) content; it might mean building on it, clarifying and extending it, in online forums or on Facebook; it could involve making a response video on You Tube or memes of your own; it might be linked with a public meeting, a march or a campaign. In this world the successful political performers will be those giving people something they can use a script (ideas, arguments, slogans) that they can take up, adapt, improvise upon. The most successful of all will connect this to an ideological proposition, giving people the chance to perform an identity which makes them part of the historical drama: a spear-thrower in the lastditch fight against the barbarians within or without; digging the foundations for the rebuilding of the Empire; a member of the chorus chanting the name of the leader who came out of the wilderness. Those who can do this will, in the future, prosper politically. Those who cannot will be have no place on stage. 
It is not sufficient to respond to this by arguing for new forms of governance for communication. Building higher walls will not protect the twentieth-century agora. Those walls have already been breached. The pressing question is why is the left not very good at developing its own popular, polemical and participatory media? It has its tribunes of course, on sites such as The Canary and the success of Momentum is in part down to a sophisticated understanding how to use digital media to effectively educate, agitate and organise and of how to link it to real-world events including those focused on political education such as the conference fringe events organised under the banner The World Transformed. ${ }^{15}$ But the left and Labour are still predominantly signed-up to the party of print and its key performers are people of the press and publishing. Owen Jones, for example, has a You Tube channel (one hundred and seven thousand subscribers) and the content is primarily an adjunct to his journalism, often involving interviews with politicians and similar in style to mainstream broadcast media.

There is no left-wing equivalent to Sargon, Benjamin or Watson. Perhaps that is a good thing. The left should not ape the Right by becoming an aggressive alt-left, purely polemical or busily producing its own fake news (although clearly that is a temptation to which some might succumb). But it is necessary to develop means of overcoming the reduction of political communication to misinformation, brand-building and self-declaration disconnected from policies, programmes and Parliaments. Doing so requires recall of the political culture of the nineteenth-century left, recreating ways which resist the individualising tendencies of the medium as presently constituted, and give rise to a politics of participation in the construction of a collective political intelligence. That cannot be done until we appreciate that political communication is not now solely or even primarily reducible to political marketing to promote a party, a policy or a programme to a general electorate. It must also be an appeal to particular 
audiences, those who want more than 'delivery' and who want to learn how to take part in the broader 'culture war' underway. That may mean reactivating genres of old - a twenty-first century version of the Fabian 'Facts for Socialists' perhaps - providing resources for understanding and argument rather better than declaring it the current year. It means not being afraid of ideological argument, of bringing forward the ethical and philosophical claims which underpin the policies we advocate, letting debate and dispute be seen as good things, part of how we apply ourselves to the problems of the present, showing how all of this must be tied to a political movement, requiring discipline of thought and speech and awareness that we stand not only for ourselves but for each other and against those who would harm our friends and take our democratic politics from us.

\footnotetext{
${ }^{1}$ For an overview of thinking into the cultural context behind this politics see Lars Rensmann, 'The Noisy Counter-Revolution: Understanding the Cultural Conditions and Dynamics of Populist Politics in Europe in the Digital Age', Politics and Governance, 5, 4, pp, 123-135, 2017.

2 See also Samanth Subramanian "Inside the Macedonian Fake-News Complex" Wired Magazine, $15^{\text {th }}$ February, 2017.

${ }^{3}$ Just one example is Azmina Dhrodia, 'We tracked 25,688 abusive tweets sent to women MPs - half were directed at Diane Abbott', New Statesman, Sept. 2017; see also The Fawcett Society campaign 'Reclaim the Internet' https://www.fawcettsociety.org.uk/reclaim-the-internet

${ }^{4}$ Simon Murdoch, 'HNH explains...trolling and the alt-right', HopenotHate.com, $10^{\text {th }}$ Oct. 2017 , https://hopenothate.com/2017/10/10/hnh-explains-trolling-alt-right/

${ }^{5}$ Regis Debray, 'Socialism: A Life Cycle', New Left Review, July-August 2007.

${ }^{6}$ Jeffrey C. Alexander, 'Cultural Pragmatics: Social performance between ritual and strategy' in Jeffrey Alexander, Bernhard Giesen and Jason Mast (eds.), Social Performance: Symbolic Action, Cultural Pragmatics and Ritual, Cambridge University Press, 2006; The Performance of Politics: Obama's Victory and the Democratic Struggle for Power, Oxford University Press, 2010.

${ }^{7}$ BBC News, June $21^{\text {st }} 2016$, 'EU Referendum: Davidson and Johnson Close Great Debate', http://www.bbc.co.uk/news/av/uk-politics-eu-referendum-36590539/eu-referendum-davidson-and-johnsonclose-great-debate

${ }^{8}$ For a larger study of these kinds of 'citations' and performances see Judi Atkins \& Alan Finlayson, ““...A 40year-old black man made the point to me": Anecdotes, Everyday Knowledge and the Performance of Leadership in British Politics', Political Studies, 61, 1, pp. 161-177, 2013.

${ }^{9}$ Robert Booth, 'DIY Political websites: new force shaping the General Election Debate', The Guardian, June $1^{\text {st }} 2017$

${ }^{10}$ On the theory of the cartel party see Richard S Katz and Peter Mair, 'Changing Models of Party Organization and Party Democracy: the emergence of the cartel party', Party Politics, 1, 1, pp. 5-31, 1995.

Parties

${ }^{11}$ Alexander R. Galloway, The Interface Effect, Polity Press, 2012.

12 This particular strategy of the right precedes the digital era and was well used, and developed, North American radio hosts and columnists throughout the nineteen-eighties and nineteen-nineties. Sam Chambers and I explored it, through the case-study of one especially sectarian commentator in 'Ann Coulter and the Problem of Pluralism: From Values to Politics', Borderlands, Vol. 7, 1, 2008.

${ }^{13}$ On the deep and intimate connection between the online Right and opposition to feminism see Annie Kelly, The alt-right: reactionary rehabilitation for white masculinity, Soundings, Issue 66.

14 This wide estimate is taken from a Patreon funded site. See Graphtreon: https://graphtreon.com/creator/jordanbpeterson
} 
${ }^{15}$ Jessica Elgot, 'Momentum building in Brighton as grassroots group goes mainstream', The Guardian, 24 ${ }^{\text {th }}$ September, 2017. 